\title{
HAND DEFORMITIES IN RHEUMATOID DISEASE
}

\author{
BY \\ D. A. BREWERTON \\ From the Department of Physical Medicine, King's College Hospital, London
}

(RECEIVED FOR PUBLICATION FEBRUARY 1, 1957)

This is a study of hand deformities in rheumatoid disease: their incidence, their causes, and their effects on function. Three hundred patients with this disease have been examined.

There can be no doubt of the importance of hand deformities to the rheumatoid patient, nor of the importance of preventing hand deformities when treating this disease. Consequently it is surprising to find that there are few detailed accounts of these deformities in the literature. Ulnar deviation and its causes have been discussed at length (Fearnley, 1951; Lush, 1952; Vainio and Oka, 1953). Some of the comımon tendon lesions have been described in detail (Edström, 1945; Kellgren and Ball, 1950; Snorrason, 1951 ; Harris, 1951 ; Ansell and Bywaters, 1953). Contractures of the intrinsic muscles of the hand due to other causes have been described fully, but there have been few details of this condition as it occurs clinically in rheumatoid disease (Kestler, 1949; Bunnell, 1953, 1955; Harris and Riordan, 1954). Of the remaining deformities, most have at least been mentioned in the literature, but only a few have been described in detail with discussion of their causes.

To place the prevention of hand deformities on a sound basis, it is essential to know more about the deformities that occur. The objects of this study were to find out the incidence of the permanent deformities occurring in the rheumatoid hand; and to discover which of these deformities were important in everyday function. Whenever possible the causes of the deformities were recorded.

\section{Material}

The patients were a typical cross-section of those seen in hospitals. No special selection was made and the three hundred patients were seen as they attended King's College Hospital and nearby hospitals in the SouthEast Metropolitan Region. Most of them were outpatients attending rheumatic clinics; a few were attending other departments for reasons unrelated to their rheumatic disease; fifteen were seen in the wards. None was bedridden.

The sex ratio, age at onset, and duration of disease are set out in Tables I and II. All age groups are represented, except that, by chance, there were no men in whom the disease had started when under 20 years of age. Almost half of the patients were in the first 5-year period of disease, but after that period their numbers steadily decreased, because of the artificial selection of hospital out-patients. Presumably many in the later years no longer attend as they have improved; a few are too disabled; and the rest have returned to the care of their general practitioners. Certainly those still attending hospital late in their disease are likely to be more disabled than the average rheumatoid patient at this stage.

TABLE I

AGE AT ONSET

\begin{tabular}{|c|c|c|c|c|c|}
\hline \multicolumn{2}{|c|}{ Age $\underset{(y r s)}{\text { at Onset }}$} & \multicolumn{2}{|r|}{ Women } & Men & Tota \\
\hline $\begin{array}{l}10-19 \\
20-29 \\
30-39 \\
40-49 \\
50-59 \\
60-69 \\
70-79 \\
80-89\end{array}$ & $\begin{array}{l}\ldots \\
\ldots \\
\ldots \\
\ldots \\
\ldots \\
\ldots \\
.\end{array}$ & $\begin{array}{l}\cdots \\
\cdots \\
\cdots \\
\cdots \\
\cdots \\
\cdots\end{array}$ & $\begin{array}{r}12 \\
37 \\
36 \\
52 \\
58 \\
30 \\
6 \\
1\end{array}$ & $\begin{array}{r}72 \\
11 \\
20 \\
19 \\
11 \\
4 \\
1\end{array}$ & $\begin{array}{r}12 \\
39 \\
47 \\
72 \\
77 \\
41 \\
10 \\
2\end{array}$ \\
\hline Total & . & .. & 232 & 68 & 300 \\
\hline
\end{tabular}

TABLE II

DURATION OF DISEASE

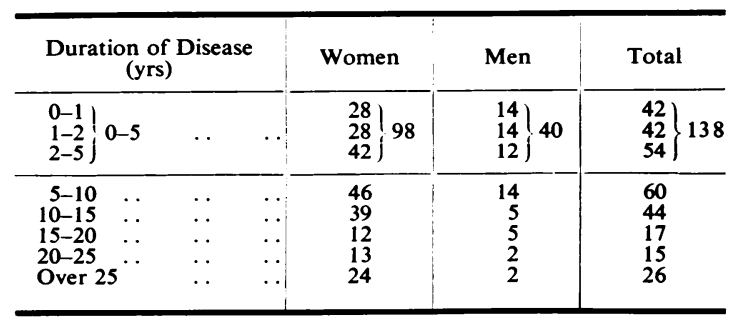

Patients whose hands were normal were included in the series. 
Three men considered for this survey were excluded as they had ankylosing spondylitis with involvement of the hands. Also excluded were two women who had psoriatic arthropathy with joint involvement confined to the distal interphalangeal joints. Four other patients with the rheumatoid type of arthritis and psoriasis were admitted to the series.

It must be stressed that the majority of patients were seen, for the purpose of this survey, at only one stage in the course of their disease. It was possible to follow only a few patients through a period when permanent deformities were developing. The incidence of various deformities are given in a later section of this paper. These figures must be interpreted with the understanding that many cases were of recent onset and had yet to develop their deformities, whereas others in whom the disease was of longer duration had such joint stiffness that the original deforming factors had become obscured.

\section{Examination}

A study was made of the thumb and fingers, and their function. The wrist was not examined in detail.

Within the hand every structure was examined according to a detailed routine, that included individual scrutiny of each joint, tendon, and muscle. A search was made for contractures of the long flexors and extensors of the fingers within the forearm, and for involvement of their tendons at the wrist.

Wrist function was tested only to establish that it had no major effect on hand deformities. Record was kept of pronation and supination of the forearm, wrist movements, and clinical involvement of the tendons of the wrist flexors and extensors.

The detailed examination was followed by tests of hand function to find out which deformities were most important. Four basic grips were used (Fig. 1).

Grip 1 (Fig. 1a).-To pick up and manipulate small objects it is essential to oppose the thumb and one of the fingers. The thumb must be capable of opposition, and the finger must be capable of flexion, particularly at the proximal interphalangeal joint. If this grip is impossible, the patient will be unable to do up buttons, sew, or pick up small objects.

Grip 2 (Fig. 1b).-The second grip is required for turning keys or gas taps. Its basis is a strong grip between thumb and finger. Opposition of the thumb and finger are required as for Grip 1, but other factors are added. The joints of both thumb and finger must be stable; the intrinsic muscles must be strong; and pain must not be severe.
Fig. 1a.-Grip 1.

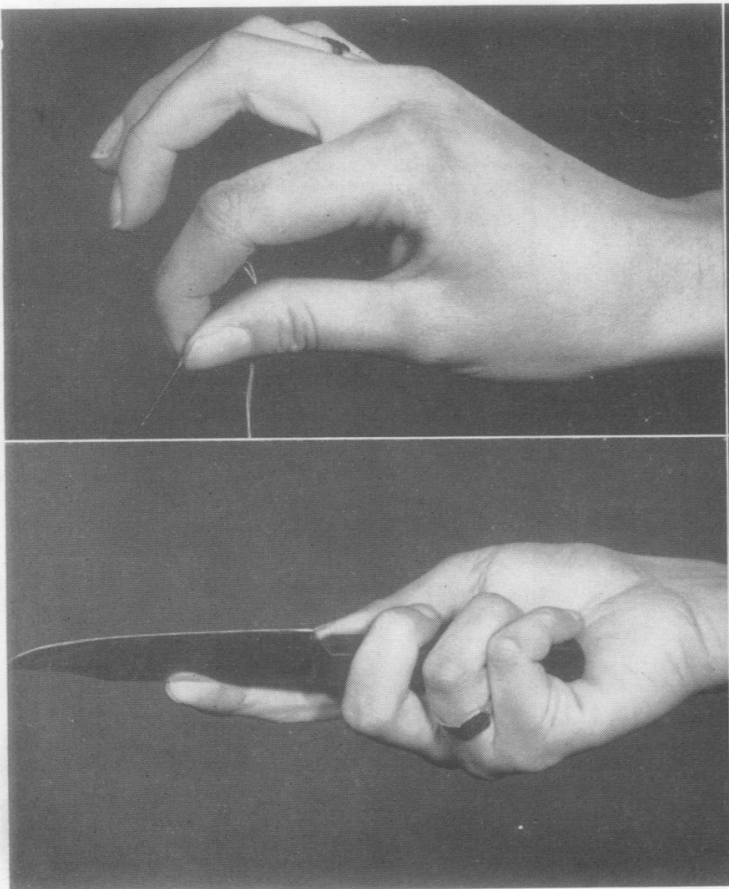

Fig. 1c.-Grip 3.
Fig. 1b.-Grip 2
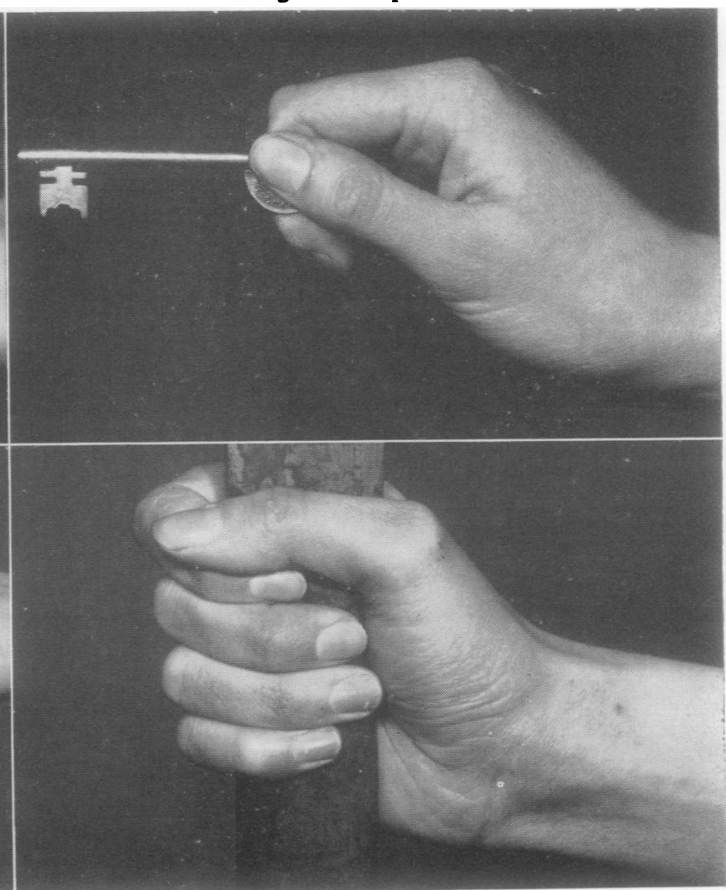

Fig. 1d.-Grip 4.

Figs 1 a-d. Normal hand, using four basic grips. 
Grip 3 (Fig. 1c).-For using objects with a handle, such as a knife, the grip is complex, involving two separate processes. First there is a firm grip between the thumb, index, and middle fingers with all the requirements of Grip 2. Then the handle is steadied by a grip between the ring and little fingers, and the thenar eminence or palm. This grip and related modifications are commonly used in daily activities. The point to realize is that the handle is held obliquely across the palm. This makes loss of flexion in the ring and little fingers a most important deformity of far greater functional significance than loss of flexion in the index and middle fingers.

Grip 4 (Fig. 1d).-A stronger grip is required for pulling on hand-rails or the firm use of a hammer. Without this grip it is almost impossible to board a bus unaided. Adequate abduction of the thumb is necessary to get the object into the palm of the hand, and then the fingers must flex at least so that they can act as a hook. Severe loss of flexion at the proximal interphalangeal joints makes this grip impossible and is, therefore, a serious disability as it prevents many activities useful to the arthritic.

All the patients attempted these four grips, and, in addition, a few patients were observed at greater length while doing a representative series of everyday tasks.

\section{Natural History of Hand Deformities}

The early stages of rheumatoid disease are characterized by active inflammation of the joint structures, tendons, and intrinsic muscles. Usually this inflammation is mild and progression to deformity is slow. The joints may be swollen, stiff, and painful. Tendon involvement may cause pain, "triggering", and difficulty in active finger flexion. The intrinsic muscles may exhibit spasm that can be overcome only with difficulty.

After weeks, months, or years, the active inflammation usually becomes less. The joint swelling subsides, and the range of movement increases. Tendon lesions also improve, so that triggering may cease and active flexion return. Intrinsic muscle spasm usually disappears.

This leaves a mixture of low-grade active inflammation and permanent deformity; but in most patients the permanent deformities gradually assume greater importance, so that it is they and not the active inflammation that prevent function. The disability is then more stable although there may be super-added fluctuations in the activity of the disease. Usually function is better in this later stage, and progressive deterioration is the exception. In a few patients, the hands become normal both in function and on clinical examination.

Permanent deformities may arise in the joints, the tendons, or the small muscles of the hands. Any joint may become restricted in range by involvement of its own structures. Alternatively, stretching or destructive processes may lead to increased joint mobility in any direction. This includes rupture of ligaments, and subluxation or dislocation of joints. Tendon lesions are common and may cause difficulty in active extension or flexion, even when the joints are mobile. The tendons may be dislocated, stretched, or ruptured. The intrinsic muscles may be weak; and they are often the site of contractures which hamper joint movement and may lead to joint deformity.

The mixture of these deformities and deforming factors is capable of infinite variation so that two cases are seldom alike. It is only by analysing a large number of cases that any deformity is seen in all its guises, and patterns of development become apparent.

\section{Loss of Finger Flexion due to Joint Deformities}

Four sets of joints contribute to finger flexion: the carpo-metacarpal joints of the ring and little fingers, the metacarpo-phalangeal joints, the proximal interphalangeal joints, and the distal interphalangeal joints. Of these, the metacarpo-phalangeal and proximal interphalangeal joints are the most important.

For everyday function, flexion is more valuable than extension. Also, flexion of the ring and little fingers is more important than flexion of the index and middle fingers. This is because the index and middle fingers function with the thumb, while the ring and little fingers are often expected to exert a stabilizing influence by compressing a handle against the palm or thenar eminence (Fig. 1c).

The carpo-metacarpal joints of the ring and little fingers have only a small range of flexion and extension, but this small range is important for opposition and full flexion of these fingers. If flexion of these joints is abolished, it is usually impossible for the finger tips to reach the thenar eminence.

In rheumatoid disease, the range of movements in these joints may be decreased or increased. It was decreased in 26 per cent. of the patients, with ankylosis in 12 per cent. Fortunately, this ankylosis caused little disability as it was usually in a flexed position. Sometimes it was in a position considerably more flexed than is normally possible, and this was an asset if other finger joints were unable to flex fully. Almost invariably, ankylosis of the carpo-metacarpal joints was associated with ankylosis of the wrist. The range of movement was increased in 26 patients ( 9 per cent.), and in a few flexion was possible to two or three times the normal range. This was a considerable advantage. 
The metacarpo-phalangeal joints normally flex to $90^{\circ}$, with the little finger flexing $15^{\circ}$ more than this, and the index finger $15^{\circ}$ less. Even a few degrees loss of flexion is important in the ring and little fingers. By contrast, a $30^{\circ}$ loss of flexion in the index and middle fingers usually has little effect on function unless there is also loss of flexion in the interphalangeal joints.

A $10^{\circ}$ loss of flexion in one or more fingers was found in 37 per cent. of the patients (Table III), but in 10 per cent. this was confined to the index and middle fingers and had virtually no effect on function.

An increased range of flexion at the metacarpophalangeal joints was seen in nine patients $(3$ per cent., Table III). All of them had dislocation or severe subluxation of these joints, and all but one also had ulnar deviation. This increased flexion is, of course, an asset and explains the excellent function in some patients whose deformities look severe.

TABLE III

DEFORMITIES IN METACARPO-PHALANGEAL JOINTS OF FINGERS

\begin{tabular}{|c|c|c|c|c|c|c|}
\hline \multicolumn{6}{|c|}{ Deformity } & Percentage \\
\hline \multicolumn{6}{|c|}{ Loss of Passive Extension (Less than $170^{\circ}$ ) .. } & 22 \\
\hline \multicolumn{6}{|c|}{ Loss of Passive Flexion (More than $10^{\circ}$ Loss) } & 37 \\
\hline \multicolumn{3}{|c|}{ Increased Range of Extension } & . & . & $\cdots$ & 2 \\
\hline \multicolumn{2}{|c|}{ Increased Range of Flexion } & $\cdots$ & $\cdots$ & . & $\cdots$ & 3 \\
\hline Ulnar Deviation & . & . & $\cdots$ & . & $\cdots$ & 27 \\
\hline Radial Deviation & . & $\cdots$ & $\cdots$ & $\because$ & $\cdots$ & $0 \cdot 3$ \\
\hline Anterior Subluxation & . & $\ldots$ & . & $\therefore$ & $\ldots$ & 20 \\
\hline "Normal" & $\ldots$ & . & . & . & $\cdots$ & 42 \\
\hline
\end{tabular}

The proximal interphalangeal joints normally flex to beyond $90^{\circ}$. A few degrees of flexion loss is usually well tolerated. What makes this type of deformity important is the severe flexion loss that may occur (Fig. 2). Again, the effect on function depends on the fingers involved. The importance of the ring and little finger deformities is best judged by the ability to hold a knife with a thin handle. The critical angle is $120^{\circ}$, for inability to flex to that angle usually means that the knife cannot be gripped firmly. The index and middle fingers can pick up and handle small objects with the help of the thumb, provided that the proximal interphalangeal joints in these fingers can flex to $135^{\circ}$. Severe loss of flexion in all the joints may prevent the gripping of large objects such as a hand-rail or a crutch.

35 per cent. of the patients were unable to flex all their proximal interphalangeal joints to $90^{\circ}$. All grades of flexion loss were seen and it was considered to be severe in 14 per cent.

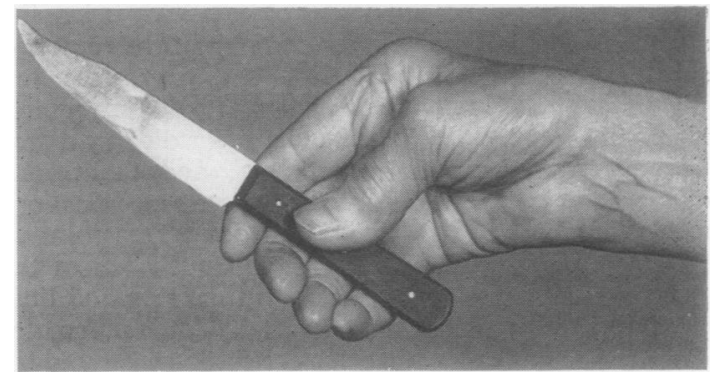

Fig. 2.-Severe loss of flexion at proximal interphalangeal joints resulting in feeble grip. This patient is fortunate in having a mobile thumb.

The principal cause of flexion loss is rheumatoid involvement of the joints themselves but two other contributory factors were seen. Hyperextension of these joints (page 189) may lead to severe flexion loss, and the joints may even become fixed in hyperextended positions (Fig. 5b). Lack of treatment in the early stages may also play a part, although its importance is difficult to estimate. One unfortunate woman had had both hands bandaged to long splints for 9 months, without physiotherapy to maintain the joint range. As a consequence all the metacarpo-phalangeal and interphalangeal joints of both hands had become ankylosed in an extended position.

The distal interphalangeal joints lose their ability to flex about as often as the proximal joints, but function is seldom affected and the deformities usually pass unnoticed.

Loss of Finger Extension due to Joint Deformities

Loss of extension of the fingers is not as disabling as loss of flexion, unless it is severe. However, it may make it impossible to hold a large object, such as a glass tumbler or even a hand-rail.

The metacarpo-phalangeal and proximal interphalangeal joints contribute most to extension. Loss of extension of the carpo-metacarpal and distal interphalangeal joints was found to have little effect on function.

The metacarpo-phalangeal joints can normally be extended to beyond $180^{\circ}$, and in some people to $240^{\circ}$.

Fixed flexion must be marked to affect function, and in only 4 per cent. was it impossible to extend all the metacarpo-phalangeal joints beyond $135^{\circ}$. Lesser degrees of extension loss were common, 22 per cent. being unable to extend all their fingers to $170^{\circ}$ (Table III). One patient had severe fixed flexion of all his fingers making his hands virtually useless. 
Hyperextension of these joints is not a feature of rheumatoid disease, apart from occasional cases with gross joint destruction confined to one or two joints ( 2 per cent. of patients).

The proximal interphalangeal joints normally extend to $180^{\circ}$. Only 15 per cent. of patients failed to extend all their proximal interphalangeal joints to $160^{\circ}$ or beyond. Severe flexion deformities were uncommon.

As with flexion of these joints the principal cause of extension loss is rheumatoid involvement of the joints, but the incidence of this deformity depends to a certain extent on the treatment given during the early stages. Three patients were quite clear in their own minds about the onset of their difficulty, for, during an episode of acute joint inflammation, short plaster splints had been applied with the fingers curled over the ends of the splints. The result had been permanent, severe fixed flexion deformity of the proximal interphalangeal joints. A totally different cause of fixed flexion was congenital flexion deformity of the little finger. Eight patients had mild degrees of this condition until rheumatoid disease involved their hands and turned a mild deformity into a severe one.

Ulnar Deviation at the Metacarpo-Phalangeal Joints

Ulnar deviation of the fingers has always attracted attention, so that when it occurs it is often regarded as the major deformity in the joints involved. In fact, it is often associated with anterior subluxation or dislocation of the joints, lateral dislocation of extensor tendons, and other deformities that have more important effects on function than the deviation itself. Ulnar deviation is unlikely to be a serious disability unless there is associated loss of flexion in the metacarpo-phalangeal joints. The instability in a medial (ulnar) direction may weaken grips between thumb and index finger (Fig. 1b), but for this the deformity must be marked and even then the resulting disability is usually mild. The most important feature of ulnar deviation is its effect on appearance.

There is another reason for studying ulnar deviation in some detail, and that is our failure to understand its cause.

Incidence. -82 patients ( 27 per cent.) had ulnar deviation (62 women and 20 men).

Duration of Disease.-Usually, ulnar deviation does not develop early in the disease, except for a minor deviation which may be reversible. Of the patients in the first 5-year period of disease, only 9 per cent. had ulnar deviation, and in most it was mild. After that period it was much more common, being seen in 43 per cent.
Distribution.-Ulnar deviation was bilateral in 42 patients, involved the right hand only in 24 , and the left hand only in sixteen.

The medial fingers were more frequently involved in the process than the lateral fingers, and with few exceptions they were more severely involved. This applied equally to the distribution of ulnar deviation, anterior subluxation, and tendon dislocation. In eight patients the little finger alone was involved. Apart from its greater tendency to be involved, the little finger was often deformed in a way that is unique, for it alone is capable of true ulnar dislocation.

Anterior Subluxation or Dislocation.-This was found combined with ulnar deviation in 44 of the 82 patients. This association does not occur because one condition is a complication of the other, for the two usually develop together. They should not be considered as two separate processes, for in this group of patients the subluxation is in an antero-medial direction from the start (Fig. 3, overleaf).

It is valuable to distinguish this group in which subluxation is partly in an anterior direction, because it includes most of the cases with severe ulnar deviatio When seen early in the course of the disease, mild ulnar deviation is more likely to progress to an unsightly deformity if there is also anterior subluxation. But, even if a severe and unsightly deformity develops, the function of the hand may be excellent, because the range of joint flexion is usually maintained or actually increased.

When anterior subluxation is present, both it and the ulnar deviation usually become worse when the metacarpo-phalangeal joints are flexed actively. This was demonstrated very clearly in two patients, for in them no abnormality was noted except during active flexion. As the fist was clenched, sudden anterior subluxation occurred and was followed by marked ulnar deviation as the grip was tightened.

Dislocation of Extensor Tendons to the medial side of the metacarpo-phalangeal joints was seen in fifty of the 82 patients with ulnar deviation. Snorrason (1951) suggested that this was one cause of ulnar deviation, but subsequent authors have disagreed, on the grounds that it occurs only in patients with severe ulnar deviation (Fearnley, 1951). In the present series, tendon dislocation was seldom a primary cause of ulnar deviation, and was usually considered to be a complication of ulnar deviation due to other causes. However, three patients gave a clear history of sudden episodes which must have been due to spontaneous tendon dislocation. These episodes were followed immediately by the onset of 


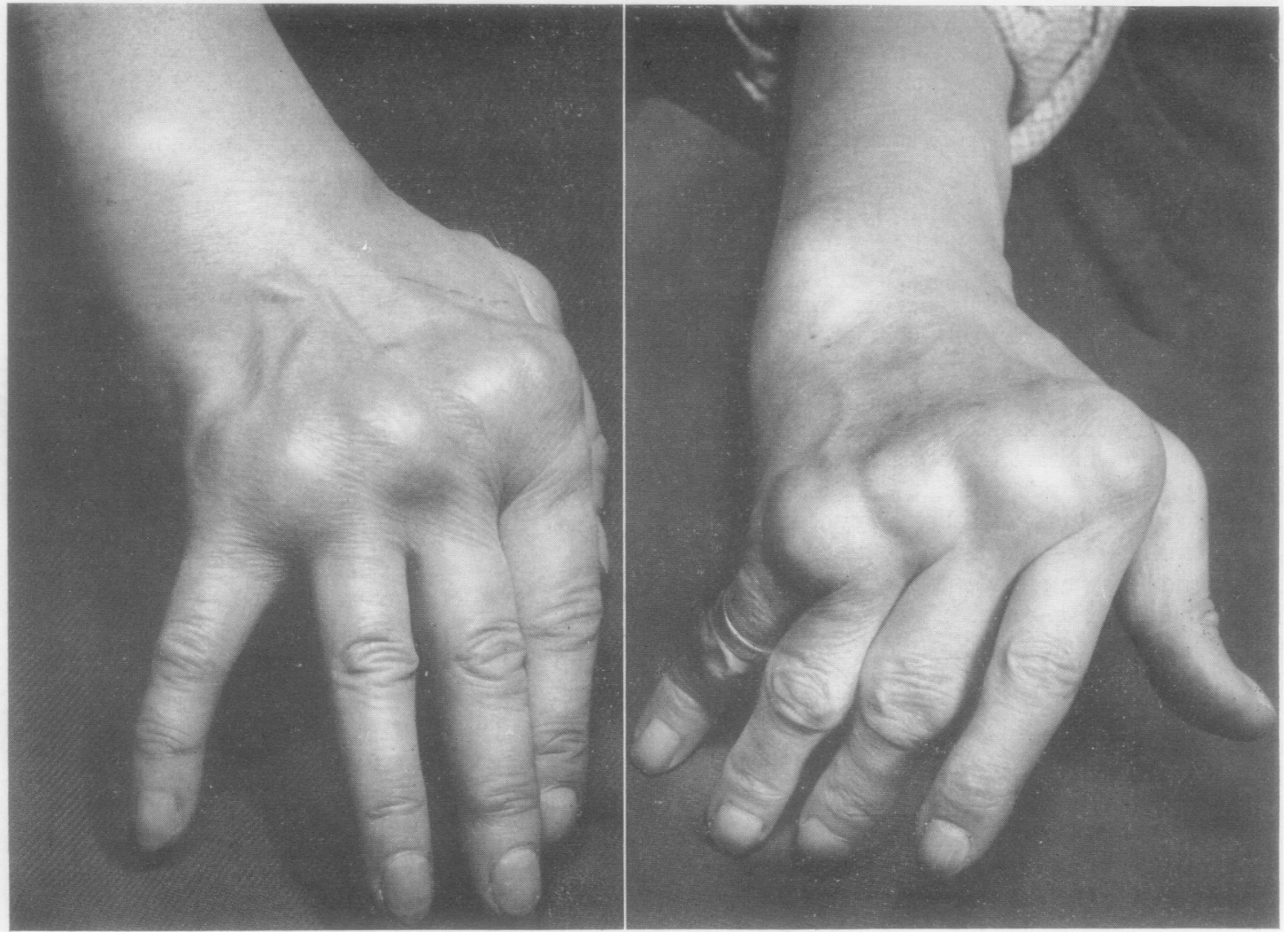

Fig. 3.- Two patients with similar deformities at different stages. Four basic abnormalities are seen in the more deformed hand: anterior subluxation and ulnar deviation of metacarpo-phalangeal joints, lateral dislocation of extensor tendons, and flexion of carpometacarpal joints of ring and little fingers.

In the less deformed hand. mild anterior subluxation and ulnar deviation have developed together. especially in the little finger.

ulnar deviation in the affected fingers. The dislocation of tendons usually starts in the little finger and spreads to involve the more lateral fingers. It is unusual to find dislocation of a lateral tendon without all the more medial tendons being dislocated. Occasionally, however, ulnar deviation is surprisingly marked in the middle or index fingers, and this is always associated with tendon dislocation confined to those fingers. Under these circumstances the tendon dislocation is probably playing a primary role in the production of ulnar deviation.

What is more important is that tendon dislocation usually aggravates pre-existing ulnar deviation. The pull of the tendons is no longer along the line of the fingers, so that active extension of the metacarpo-phalangeal joints leads also to increased ulnar deviation. In addition, the dislocated tendons may be inefficient in their normal task of active extension. This was seen in approx- imately one-third of the patients with dislocated tendons (Fig. 4).

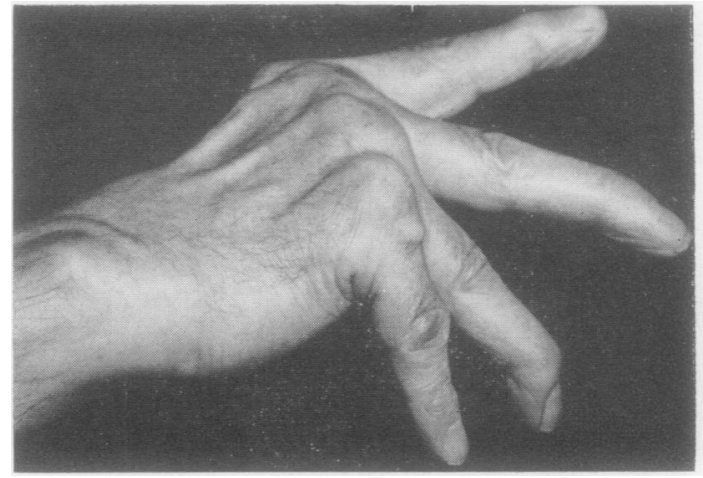

Fig. 4.-Lateral dislocation of extensor tendons preventing active extension in presence of full passive range of metacarpo-phalangeal joints. Full active extension of the middle finger was possible if the ulnar deviation was corrected passively and the dislocated tendon replaced. 
Contractures of the Intrinsic Muscles of the Hand. - These contractures probably contribute to the development of ulnar deviation, but it is difficult to know how important they are. In half the patients with ulnar deviation, joint stiffness made it impossible to test adequately for the presence of muscle contractures. But nineteen of the remaining forty patients had clearly demonstrable contractures, and in some, at least, these contractures probably contributed to the development of ulnar deviation. Three patients were particularly interesting, for there seemed little doubt that muscle contractures were a primary cause of their ulnar deviation. One man first attended with a minor tenosynovitis of the extensor tendons. There was no clinical or radiological evidence of joint involvement, but 8 months later intrinsic muscle contractures developed in both hands. These increased rapidly in severity, and were followed by ulnar deviation and mild anterior subluxation. Only then was there mild swelling of the metacarpo-phalangeal joints.

Flexion and Extension of the Metacarpo-Phalangeal Joints.-Loss of passive flexion associated with ulnar deviation affects function far more than the ulnar deviation itself, but fortunately the incidence of flexion loss is no higher than among patients without ulnar deviation. Increased flexion was seen in eight of the patients with both ulnar deviation and anterior subluxation. This was usually an important asset, as it helped to compensate for stiffness in the interphalangeal joints.

By contrast, half the patients with ulnar deviation had loss of passive extension of their metacarpophalangeal joints, so that extension loss was more common than in the absence of ulnar deviation.

Summary.-The cause of ulnar deviation is still not understood fully, although it appears to be due to several different factors. In the normal hand, there is a greater range of finger movement in an ulnar than a radial direction; and most hand grips tend to increase ulnar deviation. Rheumatoid processes in and around the metacarpo-phalangeal joints undoubtedly contribute to both ulnar deviation and anterior subluxation of these joints. Furthermore, intrinsic muscles contractures and lateral dislocation of tendons have been seen to be primary causes in a small number of patients. The problem is to know how much each of these factors contributes to the development of ulnar deviation.

\section{Radial Deviation at the Metacarpo-Phalangeal Joints}

One patient had the unusual deformity of radial deviation. Although she had had the disease for 20 years, little joint destruction had taken place, and the outstanding features were marked contractures of the intrinsic muscles, hyperextension of the proximal interphalangeal joints, and radial deviation in the left hand. It is probable that the deviation was due to the muscle contractures, but no reason was found for its radial direction.

\section{Anterior Subluxation of the Metacarpo-Phalangeal Joints}

Anterior subluxation combined with ulnar deviation has already been described, and was seen in 44 patients. It was also seen without ulnar deviation in fifteen patients, but in them it was usually mild.

\section{Hyperextension of the Proximal Interphalangeal Joints}

Although extension of the proximal interphalangeal joints is normally limited to $180^{\circ}$, a few people can hyperextend their fingers. In this series, hyperextension of one or more fingers was seen in 13 per cent. of the patients (Fig. 5). The effect on function ranged from negligible to profound. The commonest difficulty was seen in attempting voluntary flexion. Even when full passive joint range was possible, the initiation of voluntary flexion from the hyperextended position was often hesitant and jerky. But the greater problem is the severe loss of passive flexion that may develop. The joints may even become fixed in

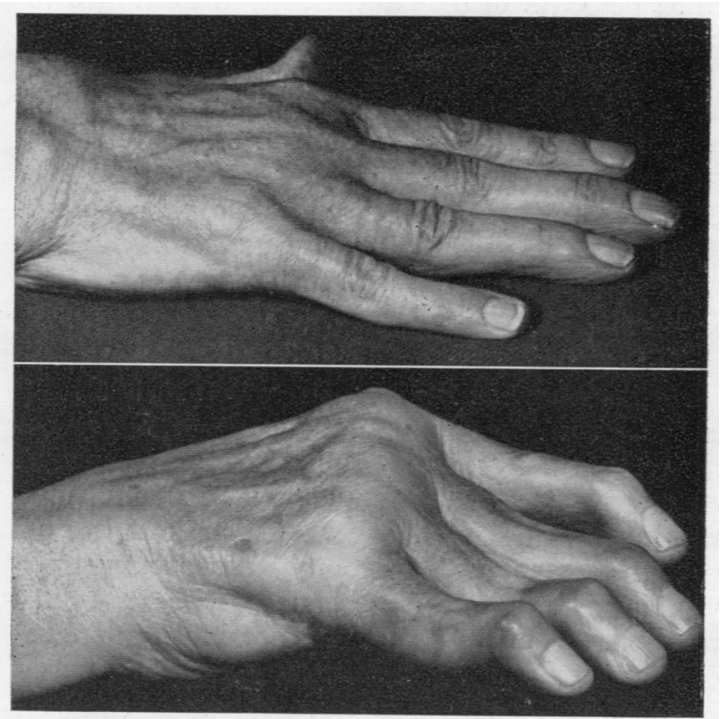

Fig. 5a.-A mild hyperextension deformity in a patient who had clearly-demonstrable intrinsic muscle contractures.

Fig. 5b.-A severe hyperextension deformity. probably due to intrinsic muscle contractures. The contractures could not be demonstrated clinically as the proximal interphalangeal joints were fixed in hyperextended positions.

Note flexion of distal joints and ulnar deviation of metacarpophalangeal joints. 
a hyperextended position. This is a catastrophe, for normal grip is then impossible however good the range of the other joints may be.

This is another deformity of which the cause is not fully understood. Occasionally it starts as a mild congenital condition and is aggravated by rheumatoid involvement. But the majority are probably due to contractures of the intrinsic muscles of the hand (see page 191).

\section{Instability of Interphalangeal Joints}

Very occasionally gross destruction of a single joint had led to general instability, or to lateral instability in either direction. No case seen in this series could be described as having "arthritis mutilans".

\section{Thumb Joints}

The deformities occurring in the thumbs are seldom striking at first sight, but they are common and may have a profound effect on function. 68 per cent. of the patients had one or more significant deformities in their thumbs.

Rotation of the Thumb.-This is a complex process, taking place in both the carpo-metacarpal and metacarpo-phalangeal joints. Internal rotation is an essential part of opposition of the thumb and is necessary for the efficient handling of small objects. In 32 per cent. of the patients, rheumatoid involvement of one or both of these joints caused $30^{\circ}$ or more loss of internal rotation. This meant that the more sensitive part of the thumb pad was not used, and also that it was difficult to pick up small objects, such as a sixpence. When the deformity was more severe, opposition was impossible, and the patient gripped objects by adducting the unrotated thumb forcibly against the index finger-the "adduction grip". This is a practical grip for many purposes but it lacks strength and is relatively clumsy.

Adduction of the Thumb.-If an "adduction grip" is to be used successfully, adduction of the carpometacarpal joint must be full. But in 11 per cent. of patients the thumb could not be adducted to within $10^{\circ}$ of the index finger. This by itself would not have been a great disability but unfortunately it was almost always associated with restricted rotation. The two deformities combined interfered considerably with grips between thumb and finger.

Abduction of the Thumb. - The handling of larger objects calls for abduction of the thumb (Fig. 1d). In 4 per cent. of patients abduction from the index finger was limited to less than $30^{\circ}$. This made it difficult or impossible to hold a hand rail or crutch.

Flexion and Extension of the Metacarpo-Phalangeal Joint.-There is little that is striking about the flexion and extension of this joint. The tendency is for the joint to be limited in range, and to be held in a semi-flexed position.

Lateral Instability of the Metacarpo-Phalangeal Joint.-This was seen in as many as 42 per cent. of the patients. In many of these the deformity was mild, but in 9 per cent. there was lateral instability of $45^{\circ}$ or more (Fig. 6). Occasionally, the onset had been sudden and had followed minor trauma, but more often it had been a gradual process, unnoticed by the patient.

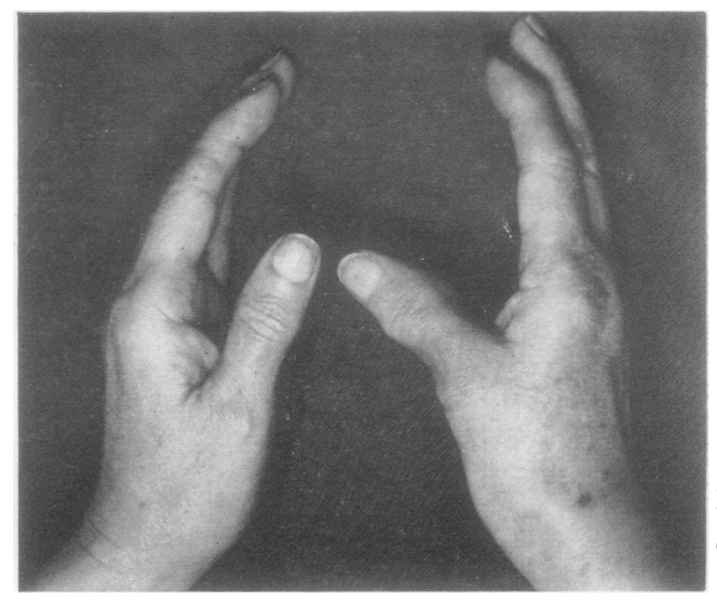

Fig. 6.-Lateral instability of metacarpo-phalangeal joint of right thumb.

The functional significance of this deformity depends largely upon the ability to oppose the thumb. If this is normal, a firm grip is possible despite the lateral instability. But when opposition is restricted and an "adduction grip" is used, lateral instability may make the grip weak and even impossible. The most pernicious combination of deformities (loss of internal rotation, loss of adduction, and lateral instability of the metacarpophalangeal joint) was seen in thirteen patients.

Flexion and Extension of the Interphalangeal Joint.-As with the metacarpo-phalangeal joint, the range of flexion and extension of the interphalangeal joint was not remarkable. It tended to be restricted, and usually the joint was in a neutral or hyperextended position.

The only notable feature is that hyperextension instability occasionally arises from joint destruction, or from flexor tendon degeneration or rupture. The effect on normal grip is obvious, but the patients avoid this and use a "proximal adduction grip", holding objects between the proximal phalanx of the thumb and the metacarpal of the index finger. 
Lateral Instability of the Interphalangeal Joint.This was seen in 6 per cent. of the patients. Occasionally the instability was so marked that the handling of small objects was impossible.

\section{Intrinsic Muscles of the Hand}

Weakness of Intrinsic Muscles.-The assessment of muscle strength in the rheumatoid hand is not simple, and consequently little can be said of its importance in the development of deformities. Wasting and weakness inevitably occur through disuse and rheumatoid involvement, but pain so inhibits muscle contraction that tests of strength are always unreliable. Also joint stiffness and deformity often mean that the muscles are working at a considerable disadvantage and appear to be weaker than they are.

In the past, intrinsic muscle weakness has been used to explain most of the deformities that occur in the hand, and the main en griffe of intrinsic paralysis has entered at least one text-book to represent the typical deformity of rheumatoid arthritis. This latter deformity was not seen, and, as far as could be ascertained, muscle weakness seemed to contribute little to the development of other deformities.

On the other hand, the effect of weakness on function is undoubted, for any grip depends on the intrinsic muscles for strength. This is particularly true if the joints are not stable. For instance, when there is ulnar deviation of all the fingers, the grip between thumb and index finger may depend to a considerable extent on the strength of the first dorsal interosseus muscle.

Spasm and Contracture of Intrinsic Muscles.Orthopaedic experience of traumatic cases during the second world war brought to prominence a characteristic deformity due to contractures of the intrinsic muscles of the hand. Ischaemia particularly may cause contracture of these muscles, in the same way that it causes Volkmann's contracture of the muscles of the forearm. The resulting deformity, when fully developed, consists of fixed flexion of the metacarpo-phalangeal joints, hyperextension of the proximal interphalangeal joints, and flexion of the distal joints. Similarity between this deformity and certain deformities due to rheumatoid disease led Bunnell $(1953,1955)$ and others to suggest that "intrinsic contractures" were common deforming factors in the rheumatoid hand.

Unfortunately this is a very difficult factor to assess. It is undoubtedly important, but just how important it is impossible to say.
TESTS.- There are two ways of demonstrating spasm or contracture of these muscles (Fig. 7). As their action is to flex the metacarpo-phalangeal joints and to extend the interphalangeal joints, their length can be estimated by attempting passive extension of the metacarpo-phalangeal joints while the interphalangeal joints are held in a flexed position. In these circumstances, the metacarpophalangeal joints can normally be extended to $180^{\circ}$. If this is not possible, the intrinsic muscles are considered to be in spasm or contracted, provided that the fault does not lie in the joint itself. The alternative method of testing is to hold the metacarpo-phalangeal joint in an extended position, and then to attempt passive flexion of the interphalangeal joints. If this flexion is restricted by contracture of the intrinsic muscles, allowing the metacarpo-phalangeal joint to flex should result in an increased range of flexion in the interphalangeal joints. It is advisable to use both of these tests, but the joints must be reasonably mobile for either test to be performed.

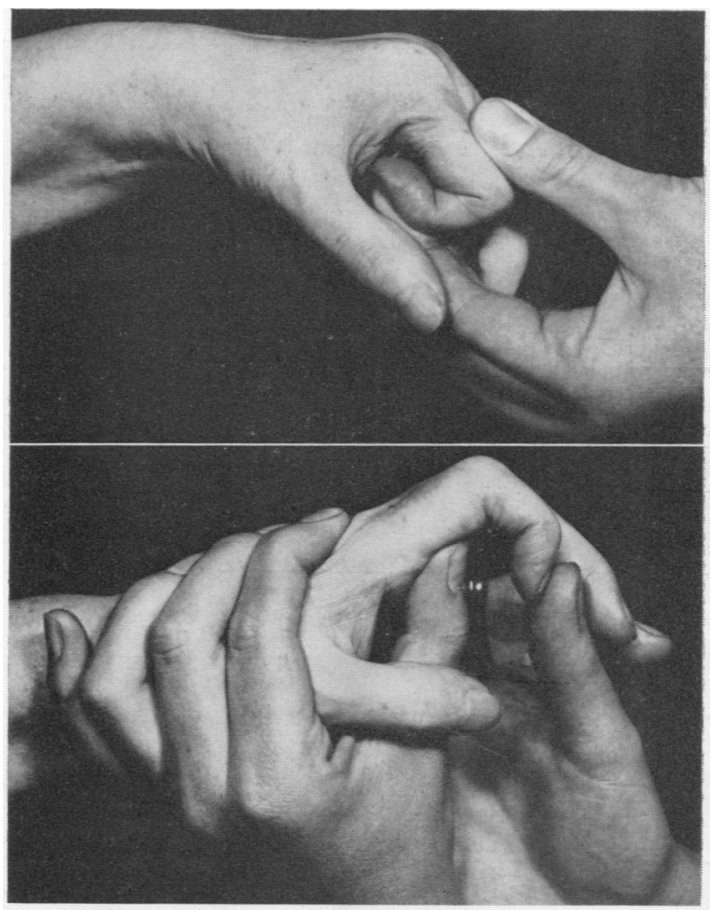

Fig. 7.-Two tests for contractures of intrinsic muscles of the hand. When the interphalangeal joints are held flexed, the metacarpophalangeal joint cannot be extended; when the metacarpo-phalangeal joint is held extended, the interphalangeal joints cannot be fully flexed.

In the first 3 years of disease most muscle shortening is due to spasm. The term "spasm" is used for three reasons: $(i)$ the shortening may be overcome with careful coaxing; (ii) it varies with fluctuations in the activity of the disease process; (iii) in a few patients it has been seen to disappear within a few days after starting cortisone therapy. 
This spasm may be seen many years after the onset, but in general it is a feature of the early stages. With time, the shortening becomes firm and constant, presumably representing the development of fibrous contracture. The most important fact is that there may be a period of one or more years between the onset of the shortening and the deformities that it may cause. During this period prevention should be possible.

It is probable that rheumatoid involvement of the muscles themselves is primarily responsible for both spasm and contracture. The pathological changes within the intrinsic muscles of the hand have been described by Kestler (1949).

In this series, 38 patients (13 per cent.) had clinically demonstrable intrinsic muscle spasm or contractures. Their presence bore no relation to the activity of the disease process in the joints or tendons, and could never be predicted without examining the muscles themselves. Of two otherwise similar hands, one might have marked contractures and the other none at all.

The deformities theoretically most likely to be

TABLE IV

INCIDENCE OF INTRINSIC CONTRACTURES IN ULNAR DEVIATION AND HYPEREXTENSION DEFORMITTIES

\begin{tabular}{|c|c|c|}
\hline Deformity & \multicolumn{2}{|c|}{$\begin{array}{l}\text { Incidence of Intrinsic } \\
\text { Contractures }\end{array}$} \\
\hline \multirow[t]{2}{*}{$\begin{array}{l}\text { Ulnar Deviation at Metacarpo- } \\
\text { phalangeal Joints }\end{array}$} & $\begin{array}{l}\text { Present } \\
\text { Absent } \\
\text { Impossible to Test }\end{array}$ & $\begin{array}{l}21 \\
19 \\
42\end{array}$ \\
\hline & Total & 82 \\
\hline \multirow[t]{2}{*}{$\begin{array}{l}\text { Hyperextension of Proximal } \\
\text { Interphalangeal Joints }\end{array}$} & $\begin{array}{l}\text { Present } \\
\text { Absent } \\
\text { Impossible to Test }\end{array}$ & $\begin{array}{l}14 \\
10 \\
14\end{array}$ \\
\hline & Total & 38 \\
\hline
\end{tabular}

caused by these contractures are ulnar deviation and anterior subluxation of the metacarpo-phalangeal joints, and hyperextension of the proximal interphalangeal joints. The difficulty in assessment is that, once these deformities are established, it is usually impossible to demonstrate the presence of the contractures (Table IV).

Ulnar deviation and anterior subluxation appear to be the direct result of intrinsic contractures in a small proportion of patients. In many more there is a less definite relationship. It is probable that these contractures are important deforming factors, but it needs a survey lasting several years to prove it.

Hyperextension of the proximal interphalangeal joints is more clearly related to intrinsic contractures. Three patients seen 3 years ago with intrinsic spasm have since developed hyperextension. There is also a relationship between the fingers with intrinsic contractures and the presence of hyperextension deformities. On the other hand, there are a few patients with definite hyperextension deformities and no evidence of intrinsic contractures.

\section{Tendons}

Of the 300 patients in this series no less than 193 (64 per cent.) had clinically demonstrable tendon lesions (Table V).

Trigger Fingers.-Rheumatoid involvement of the flexor tendons may cause "trigger" fingers. Flexion of the finger is normal, but from time to time active extension becomes impossible, and the finger must be straightened passively with help from the other hand. The pathological changes, described by Kellgren and Ball (1950), consist principally of thickening of the tendons with small masses on the surfaces of the tendons. These interfere with the movement of the tendons beneath the transverse bands that encircle them in the palm.

TABLE $\mathbf{V}$

INCIDENCE OF TENDON LESIONS

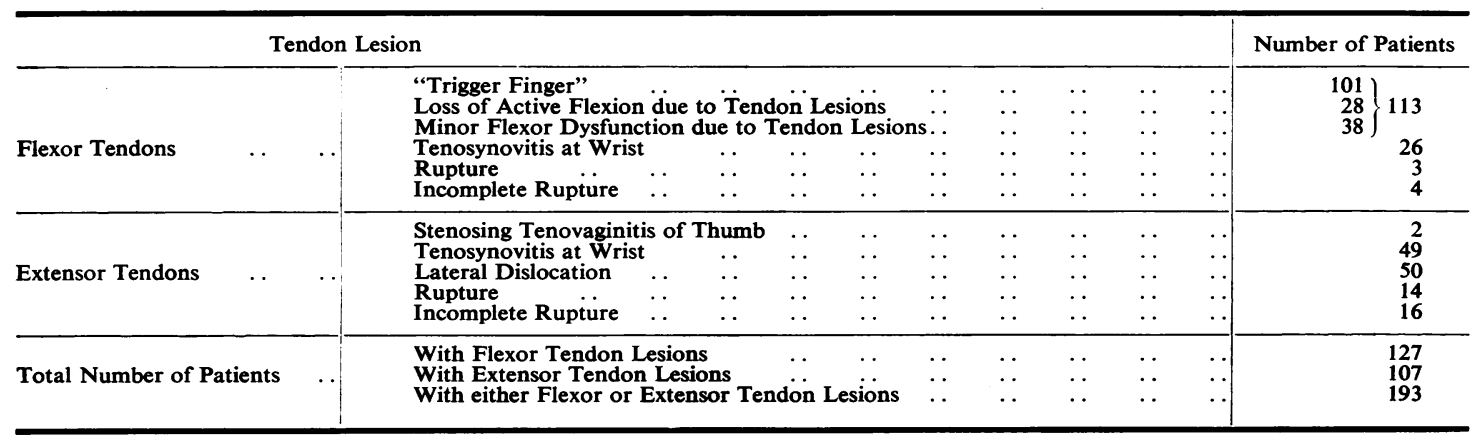


As this symptom is easily recognized and clearly described by the patients, the opportunity was taken to study the natural history of this complaint retrospectively.

101 patients ( 34 per cent.) had experienced this symptom at some time. It was twice as common among the women as among the men.

Table VI shows the incidence in different fingers. In most patients one or two fingers only were involved, but in seven patients all the fingers in one hand would become fixed in a flexed position simultaneously.

\section{TABLE VI}

DISTRIBUTION OF “TRIGGER” FINGERS

\begin{tabular}{|c|c|c|c|c|c|}
\hline \multicolumn{4}{|c|}{ Hand } & \multirow{2}{*}{$\begin{array}{r}\text { Right } \\
6 \\
24 \\
48 \\
32 \\
15\end{array}$} & \multirow{2}{*}{$\begin{array}{r}\text { Left } \\
5 \\
12 \\
31 \\
23 \\
16\end{array}$} \\
\hline $\begin{array}{l}\text { Thumb } \\
\text { Index Finger } \\
\text { Middle Finger } \\
\text { Ring Finger . } \\
\text { Little Finger . . }\end{array}$ & $\begin{array}{l}\cdots \\
\cdots \\
\cdots \\
\cdots\end{array}$ & $\begin{array}{l}\cdots \\
\cdots \\
\cdots \\
\cdots\end{array}$ & $\begin{array}{l}\ldots \\
\cdots \\
\cdots \\
\cdots\end{array}$ & & \\
\hline Total & $\ldots$ & $\ldots$ & $\ldots$ & 125 & 87 \\
\hline
\end{tabular}

Usually this symptom had started within the first 6 years of the disease. It was not uncommon as a presenting symptom, but on the other hand it had started as late as 30 years after the onset.

In the majority, spontaneous resolution had occurred within 6 months; others had lost this symptom because they became unable to flex their fingers sufficiently to elicit the symptoms; and a very small number had continued to "trigger" even for 20 or 30 years.

The disability due to triggering is very variable. It may occur several times a day; or only occasionally. It usually occurs during activities requiring repeated flexion such as peeling potatoes; but it may occur only when the hand is relaxed. It may be transitory and painless; or the patient may learn never to flex her fingers for fear of pain. It often causes patients to drop things. Rarely the finger may remain fixed in a flexed position for hours and may have to be manipulated by a doctor.

There was no relationship between a history of triggering and any permanent joint deformity. Tendon lesions may cause minor degrees of persistent flexion of the fingers (Ansell and Bywaters, 1953), but no case was seen in which significant, permanent flexion deformity could be ascribed to this cause. The incidence of permanent flexion deformity was not increased in those who gave a history of triggering.
Loss of Active Finger Flexion due to Tendon Lesions.-In addition to triggering, tendon lesions may cause loss of active finger flexion in the presence of a full and completely painless range of joint movement (Fig. 8). Kellgren and Ball (1950) state that this is due to the impaction of large nodules on the tendons between the transverse bands.

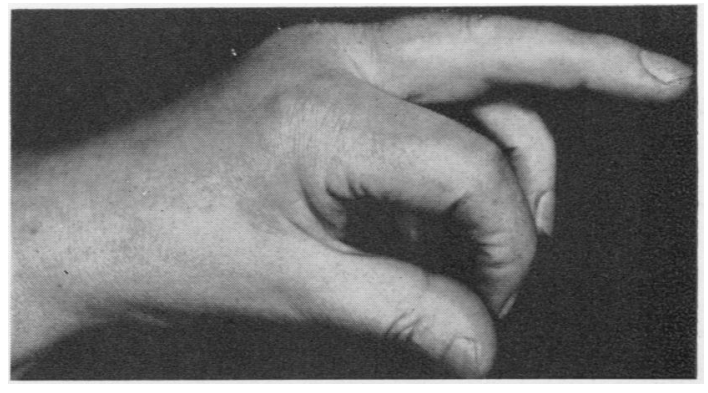

Fig. 8.-Flexor tendon lesion preventing active finger flexion despite presence of full, painless passive range of joint movement

This phenomenon is easily missed unless sought specifically. Often only one finger is involved, and the patient gets into the habit of overlapping with an adjacent finger or thumb, thereby flexing the affected finger passively and concealing the loss of function.

28 patients (9 per cent.) were found to have this disability. The index, middle, and ring fingers were affected equally.

Most of these patients also had trigger fingers, and it was usual for them to complain only of the triggering in the other fingers. They recognized the flexion loss when it was demonstrated but it was seldom the cause for spontaneous complaint. Occasionally active flexion loss can be produced by repeated flexion of a trigger finger. The two conditions are obviously related.

Unlike triggering, active flexion loss is frequently permanent. It is also more likely to disturb function by interfering with grip.

Minor Flexor Dysfunction due to Tendon Lesions. -A test for assessing the function of the flexor digitorum sublimis and its tendon (Apley, 1956) proved most useful for detecting minor flexor tendon lesions.

TEST.-All the fingers except that to be tested are held in a position of full extension. In most normal people this immobilizes the flexor digitorum profundus to all the fingers. Active flexion of the free finger, which is the one being tested, then takes place at the proximal interphalangeal joint and is due to sublimis action. If the tendons are involved, active movement may be 
hesitant, jerky, or impossible, despite full passive joint range. It should be appreciated that independent action of the sublimis tendon of the little finger is often impossible in normal people.

This test provided evidence of tendon lesions in 34 patients (11 per cent.). Many of these gave a history of triggering, and presumably the pathological changes are similar in the two conditions.

It is difficult to assess the effect of these minor lesions on everyday function. Probably it is slight, but three patients demonstrated clearly an unusual disability when picking up small objects. Normally these are gripped between the opposed thumb and a partially-flexed index finger. But in these patients movement of the flexor tendons of the index finger was erratic when the finger was partially flexed. As a result the finger was virtually uncontrollable when attempting this grip, and the hand was useless for sewing, doing up buttons, and picking up small objects.

Swelling at the Wrist due to Tenosynovitis.-The diagnosis of tenosynovitis at the wrist is often uncertain and always subject to personal interpretation. 23 per cent. of the patients were considered to have tenosynovitis of one or both wrists. This had little influence on finger or thumb function, but in a few, with minimal joint involvement, movement of the digits caused more pain at the site of the wrist swelling than in the joints that were moving.

Stenosing Tenovaginitis of the Extensor Tendons to the Thumb.-This was seen near the radial styloid in two patients, both of whom were in the early stages of disease.

Spontaneous Rupture of Tendons.--Previous accounts of spontaneous rupture of tendons in rheumatoid disease have suggested that it is uncommon (Harris, 1951). In this series, seventeen patients had between them 23 ruptured tendons that could be demonstrated clinically (Fig. 9).

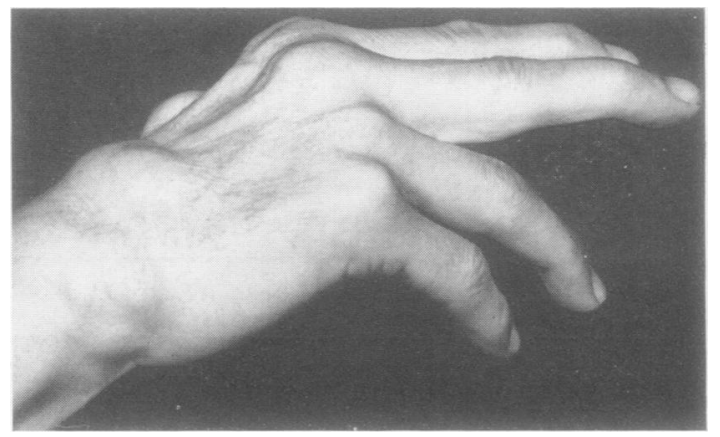

Fig. 9.--Spontaneous rupture of extensor tendons.

Table VII shows which tendons were most commonly involved. All but three were extensor tendons. Despite a careful search, rupture of flexor digitorum profundus was seen only once. It is difficult to be certain about flexor digitorum sublimis. On three occasions this tendon would not function and could possibly have been ruptured, but it is more likely that it was tethered to the accompanying profundus tendon.

\begin{tabular}{|c|c|c|c|c|c|}
\hline Tendon & & Side & Sex & $\underset{(\mathrm{yrs})}{\text { Age at Onset }}$ & $\begin{array}{c}\text { Duration of Disease } \\
\text { at Time of Rupture } \\
\text { (yrs) }\end{array}$ \\
\hline Extensor pollicis longus $\ldots$ & $\cdots$ & $\begin{array}{c}\text { Right } \\
\text { Left } \\
\text { Right } \\
\text { Right and Left } \\
\text { Right and Left } \\
\text { Left } \\
\text { Right }\end{array}$ & $\begin{array}{c}\text { Female } \\
\text { Female } \\
\text { Male } \\
\text { Male } \\
\text { Male } \\
\text { Female } \\
\text { Female }\end{array}$ & $\begin{array}{l}42 \\
52 \\
48 \\
58 \\
42 \\
30 \\
35\end{array}$ & $\begin{array}{r}1 \\
2 \\
4 \\
5 \\
9 \\
12 \\
12\end{array}$ \\
\hline Extensor pollicis brevis & . & Right & Female & 53 & 5 \\
\hline$\overline{\text { Extensor digitorum (Little finger) }}$ & $\cdots$ & $\begin{array}{c}\text { Left } \\
\text { Right }\end{array}$ & $\begin{array}{l}\text { Female } \\
\text { Female }\end{array}$ & $\begin{array}{l}17 \\
35\end{array}$ & $\begin{array}{l}16 \\
24\end{array}$ \\
\hline Extensor digitorum (Ring and little fingers) & . & $\begin{array}{l}\text { Right } \\
\text { Right } \\
\text { Right } \\
\text { Left }\end{array}$ & $\begin{array}{l}\text { Male } \\
\text { Female } \\
\text { Female } \\
\text { Female }\end{array}$ & $\begin{array}{l}47 \\
50 \\
53 \\
18\end{array}$ & $\begin{array}{r}4 \\
5 \\
6 \\
15\end{array}$ \\
\hline Flexor pollicis longus & . & $\begin{array}{c}\text { Left } \\
\text { Right }\end{array}$ & $\begin{array}{l}\text { Female } \\
\text { Female }\end{array}$ & $\begin{array}{l}38 \\
29\end{array}$ & $\begin{array}{r}7 \\
14\end{array}$ \\
\hline Flexor digitorum profundus (Little finger) & $\ldots$ & Left & Male & 40 & 5 \\
\hline
\end{tabular}


In every case the history was clear and the patient could give the key to the diagnosis: "I was cleaning the gas stove about 4 years ago when suddenly my little finger went, and it has never worked properly since." Pain is usually mild, so that it is the suddenness of the episode that is distinctive.

The disability is usually slight compared with that already present due to other deformities. Most patients said that it caused no inconvenience at all. Flexor pollicis longus was an exception, for its rupture may lead to hyperextension and instability of the interphalangeal joint, with consequent loss of grip between thumb and finger.

Previous reports have suggested that tendon rupture occurs principally in men (Harris, 1951). This was not confirmed.

Tendon rupture usually occurs in the later stages of the disease, and in only two patients had it occurred during the first 4 years.

Incomplete Rupture of Tendons.-There were several examples of incomplete rupture of tendons, and of elongation of tendons probably due to incomplete rupture with replacement by fibrous tissue.

Incomplete loss of active extension or flexion of the interphalangeal joint of the thumb was seen in a few patients. The onset had always been gradual, and active movement remained possible through a small range. When flexor pollicis longus was involved, hyperextension sometimes developed, as it did with complete rupture of this tendon.

A rheumatoid "mallet finger" may result from the occurrence of a similar process in the extensor digitorum tendon (Fig. 10).

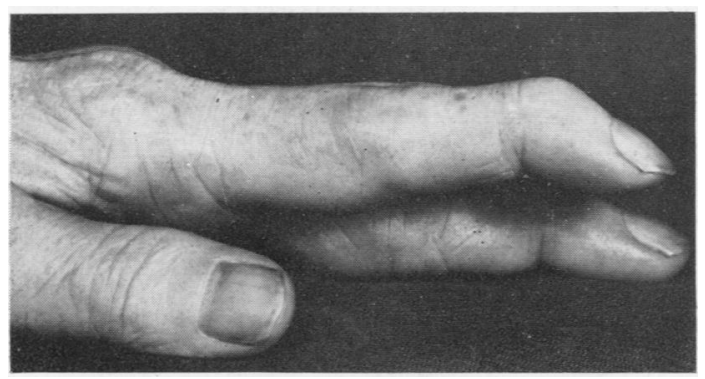

Fig. 10.-Rheumatoid "mallet finger".

Again the onset is gradual and a few degrees of active extension remain. However, these findings are not diagnostic, for exactly the same clinical picture is seen as part of the deformity resulting from contracture of the intrinsic muscles (Fig. $5 b$ ). This is the probable explanation when an apparent mallet finger is associated with hyperextension of the proximal interphalangeal joint.

"Button-hole" deformities, due to rupture of the central slips of the extensor tendons, were seen in only one patient but in her they were very striking (Fig. 11).

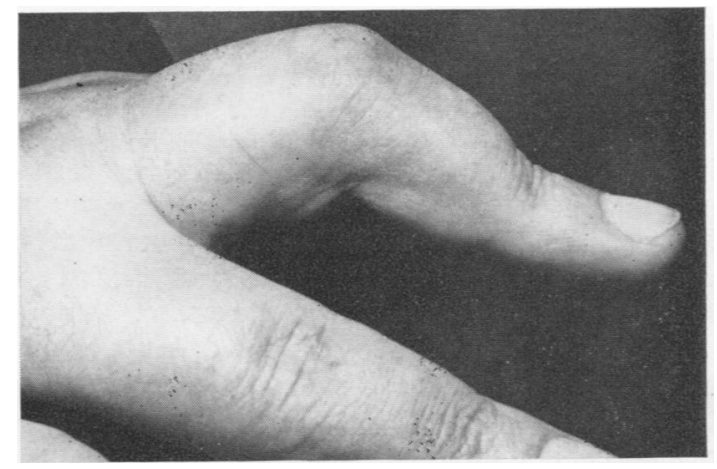

Fig. 11.-Rheumatoid "button-hole" deformity of an extensor tendon.

During the 4 months before she was examined, the middle and ring fingers of both her hands had become suddenly deformed in four separate episodes. As a result, the proximal interphalangeal joint was flexed and the distal joint extended in each finger. The more she attempted extension of the finger, the worse the flexion of the proximal joint became, although passive movements of all the joints were full. "Button-hole" deformity was confirmed at operation. The central slips of the extensor tendons were destroyed where they passed over the proximal interphalangeal joints leaving the lateral slips intact.

Dislocated Tendons. - Lateral dislocation of extensor tendons to the medial side of the metacarpophalangeal joints is part of the process of ulnar deviation and is discussed on page 187.

\section{Discussion}

The preservation of passive joint range is sometimes attempted by moving every joint through its range in each direction, without concentrating on any particular movement as being more important than others. This survey has confirmed that loss of flexion in the fingers has a far greater effect on function than an equivalent loss of extension, and that this loss of flexion is more important when it occurs in the metacarpo-phalangeal and proximal interphalangeal joints of the ring and little fingers than it is in other joints. In the thumbs, the most important movements are opposition, and adduction and abduction. It is suggested that, when passive 
or active movements are used, all joints should be exercised, but that special attention should be paid to those movements whose loss most often results in disability.

The importance of preventing contractures of the intrinsic muscles has been emphasized, particularly by Bunnell (1953, 1955) and Steindle- (1951). The exact importance of these contractures has yet to be ascertained. Nevertheless, there can be no doubt that every attempt should be made to overcome both spasm and contracture by active or passive stretching. The best method is to extend the metacarpophalangeal joints, while keeping the interphalangeal joints flexed. This is not a manoeuvre that is performed during everyday activities, but the patient can be taught to do it as a regular exercise.

Although the surgery of the hand is not within the scope of this paper, it seems that further attention should be paid to instability of the metacarpophalangeal and interphalangeal joints of the thumb. This may be very disabling, and arthrodesis or ligament repair can restore useful function. So far, three patients in the survey have had operations of this kind. The indications for surgery on rheumatoid tendons are not clear, and could probably be clarified by further studies of the natural history of tendon lesions. It is significant that the majority of patients with a history of "trigger" finger had lost this symptom within 6 months of its onset.

Several problems remain unanswered by a survey of this type, in which patients are seen at only one stage in the course of their disease. We know too little of the natural history and prognosis of many of the individual deformities in the hand. We also need to know more about the effects of drugs, physical measures, and surgery, on individual lesions and on the prevention of deformity.

\section{Summary}

Three hundred patients with rheumatoid disease were examined clinically to determine what deformities had developed in their hands, and what effect these had on function. When possible the causes of the deformities were recorded.

Any joint in the hand may become restricted in range. Loss of flexion of the fingers is more important than an equivalent loss of extension; and loss of flexion in the ring and little fingers is more important than it is in the index and middle fingers. In the thumb, loss of opposition is common, and loss of adduction or abduction are important in the few patients in which they occur.

Increased joint range is an advantage when it occurs in flexion of the carpo-metacarpal or metacarpo-phalangeal joints of the fingers. It is a disadvantage when it occurs in lateral deviation of the metacarpo-phalangeal joint of the thumb. The importance of ulnar deviation of the metacarpophalangeal joints of the fingers has been exaggerated in the past.

The intrinsic muscles of the hand may be the site of fibrous contracture. This can cause hyperextension of the proximal interphalangeal joints, and probably contributes to ulnar deviation in some patients.

Tendon lesions are common. "Trigger" fingers usually resolve, leaving no permanent deformity. Loss of active finger flexion due to tendon lesions may lead to permanent disability with secondary joint stiffness. When there is ulnar deviation there may also be dislocation of extensor tendons. Spontaneous rupture of tendons is not uncommon.

Certain aspects of treatment are discussed in the light of these findings.

I wish to thank Dr. F. S. Cooksey, Mr. H. L.-C. Wood, Dr. B. E. W. Mace, and Dr. M. E. Fearnley for their advice and criticism.

I am also indebted to the staff for arranging extra clinics; the patients for attending them; and Mr. Smith for his excellent photography.

\section{REFERENCES}

Addison, N. V. (1954). Brit. J. Surg., 41, 511.

Ansell, B. M., and Bywaters, E. G. L. (1953). Annals of the Rheumatic Diseases, 12, 283.

Apley, A. G. (1956). Brit. med. J., 1, 25.

Aunnell, S. (1953). J. Bone Jt Surg., 35A, 88.

Bunnell, S. (1953). J. Bone Jt

Burt, B. Quoted by Ray, M. B. (1933). Proc. roy. Soc. Med., 27, 193.

Coste, F. (1955). Sem. Hôp. Paris, 31, 3261

Edström, G. (1945). Nord. Med., 25, 379.

Fearnley, G. R. (1951). Annals of the Rheumatic Diseases, 10, 126.

Garrod, A. B. (1876). "A Treatise on Gout and Rheumatic Gout." 3rd ed., pp. 52, 509 . Longmans, Green, London.

Harris, C., and Riordan, D. C. (1954). J. Bone Jt Surg., 36A, 10.

Harris, R. (1951). Annals of the Rheumatic Diseases, 10, 298.

Kellgren, J. H., and Ball, J. (1950). Ibid., 9, 48.

Kelly, M. (1950). Med. J. Aust., $2,1$.

Kestler, O. C. (1949). Annals of the Rheumatic Diseases, 8, 42

Kestler, O. C. (1949). Annals of the Rheumatic Diseases, 8, 42.

Lush, B. (1952). Annals of the Rheumatic Diseases, 11, 219.

Snorrason, E. (1951). Acta med. scand., 140, 359.

Steindler, A. (1951). J. Bone Jt Surg., 33A, 849.

Vainio, K., and Oka, M. (1953). Annals of the Rheumatic Diseases, 12, 122.

Déformations des mains dans la maladie rhumatismale

\section{RÉSUMÉ}

Trois cents malades atteints de maladie rhumatismale ont subi un examen clinique afin de déterminer quelles déformations s'étaient développées dans leurs mains et quels effets elles avaient sur la fonction. Quand c'était possible, les causes des déformations ont été signalées.

Toute articulation de la main peut voir son amplitude limitée. La perte de flexion dans les doigts est plus importante qu'une perte équivalente d'extension; et la perte de flexion dans l'annulaire et l'auriculaire est plus importante qu'elle ne l'est dans l'index et le médius. 
Dans le pouce, la perte de l'apposition est commune et la perte d'adduction ou d'abduction est importante chez les quelques malades chez qui elle se produit.

L'augmentation d'amplitude de l'articulation est un avantage quand elle intéresse la flexion des articulations carpo-métacarpiennes ou métacarpo-phalangiennes. C'est un inconvénient quand elle intéresse la déviation latérale de l'articulation métacarpo-phalangienne du pouce. L'importance de la déviation cubitale des articulations métacarpo-phalangiennes des doigts a été exagérée dans le passé.

Les muscles intrinsèques de la main peuvent être le siège de contractures fibreuses. Ceci peut provoquer l'hyperextension des articulations proximales interphalangiennes et contribue probablement à la déviation cubitale chez quelques malades.

Les lésions des tendons sont communes. Les "doigts à ressort" disparaissent d'ordinaire, sans laisser de déformation permanente. La perte de flexion active des doigts par lésion des tendons peut conduire à une incapacité permanente avec raideur articulaire secondaire. Quand il y a déviation cubitale, il peut y avoir aussi luxation des tendons extenseurs. La rupture spontanée des tendons n'est par rare.

Certains aspect du traitement sont discutés à la lumière de ces données.

\section{Deformaciones de las manos en la enfermedad reumatoide} Sumario

Tres cientos pacientes con enfermedad reumatoide fueron examinados clínicamente para determinar las deformaciones de las manos y sus efectos sobre la función. Las causas de las deformaciones fueron señaladas cuando fuera posible.

Cualquier articulación de la mano puede tener su amplitud limitada. La pérdida de flexión en los dedos es más importante que una pérdida equivalente de extensión; y la pérdida de flexión en el anular y el meñique es más importante que en el índice y en el medio. En el pulgar la pérdida de la aposición es frecuente y la pérdida de aducción o de abducción es importante en los pocos enfermos en que ocurre.

El aumento de amplitud de una articulación es una ventaja al tratarse de la flexión de las articulaciones carpo-metacarpeanas o metacarpo-falangeanas de los dedos, pero es una desventaja en el caso de desviación lateral de la articulación metacarpo-falangea del pulgar. La importancia de la desviación ulnar de las articulaciones metacarpo-falangeas de los dedos ha sido exagerada en el pasado.

Los músculos intrínsecos de la mano pueden sufrir contracturas fibrosas. Esto puede provocar la hiperextensión de las articulaciones proximales interfalangeas, probablemente contribuyendo así a la desviación ulnar en algunos enfermos.

Las lesiones de los tendones son frecuentes. Los "dedos a gatillo" suelen resolverse, sin deformación permanente. La pérdida de flexión activa de los dedos por lesión tendinosa puede llevar a una incapacidad permanente con rigidez articular secundaria. Cuando hay desviación ulnar, la dislocación de los tendones extensores puede ocurrir. La rotura espontánea de tendones no es excepcional.

A la luz de estos datos se discuten ciertos aspectos del tratamiento. 